J. Lake Sci. (湖泊科学), 2014, 26(6): 829-836

http://www. jlakes. org. E-mail : jlakes@niglas.ac.cn

(c) 2014 by Journal of Lake Sciences

\title{
太湖西北部典型疏浚/对照湖区内源性营养盐释放潜力对比
}

\author{
陈 超 ${ }^{1,2}$, 钟继承 ${ }^{* * *}$, 邵世光 ${ }^{3}$, 刘 成 ${ }^{1,2}$, 范成新 ${ }^{1}$ \\ ( 1 :中国科学院南京地理与湖泊研究所湖泊与环境国家重点实验室,南京 210008) \\ (2: 中国科学院大学, 北京 100049) \\ (3:河海大学水文水资源学院,南京 210098)
}

\begin{abstract}
摘 要: 通过采集太湖西北部问江口、八房港、月亮湾和竺山湾疏浚区与未疏浚对照区 8 个样点共 32 根沉积物柱状样于 室内进行内源负荷模拟研究和沉积物基本性质分析发现,除问江口疏浚区沉积物总磷和可交换态磷含量高于未疏浚区 外,其余指标如烧失量、总氮、可交换态氮等均表现为未疏浚区沉积物高于疏浚区沉积物的特征,说明疏浚区沉积物营养 盐的释放潜力低于未疏浚对照组. 八房港、月亮湾以及䇥山湾疏浚区沉积物铵态氮、正磷酸盐的潜在释放速率均比相应 未疏浚对照区沉积物低, 疏浚区沉积物铵态氮的潜在释放速率分别是未疏浚区的 $65.3 \% 、 88.8 \%$ 和 $21.9 \%$,正磷酸盐的 潜在释放速率分别是未疏浚区的 $-26.6 \% 、 11.3 \%$ 和 $50.2 \%$. 而问江口疏浚区沉积物铵态氮和正磷酸盐的潜在释放速率 却远高于未疏浚区 (疏浚区分别为未疏浚区的 2.6 倍和 6.4 倍), 这可能与问江口水体呈现弱还原环境及沉积物中有机 质含量高有关,另外也可能与问江口沉积物污染物的赋存深度和疏浚工程的疏浚深度有关.
\end{abstract}

关键词: 底泥疏浚;潜在释放速率;效果评估;太湖

\section{On the potential release rates of nutrient from internal sources: A comparative study of typical dredged and un-dredged areas, northwestern Lake Taihu}

\author{
CHEN Chao ${ }^{1,2}$, ZHONG Jicheng $^{1}$, SHAO Shiguang ${ }^{3}$, LIU Cheng ${ }^{1,2}$ \& FAN Chengxin ${ }^{1}$ \\ (1: State Key Laboratory of Lake Science and Environment, Nanjing Institute of Geography and Limnology, Chinese Academy \\ of Sciences, Nanjing 210008, P. R. China) \\ (2: University of Chinese Academy of Sciences, Beijing 100049, P. R. China) \\ (3: College of Hydrology and Water Resources, Hohai University, Nanjing 210098, P. R. China)
}

\begin{abstract}
Simulated research of internal loading release was carried out to assess the effects of sediment dredging on internal source release, and the basic properties of dredged and un-dredged sediments was also analyzed in this study. Intact sediment cores were collected from dredged and un-dredged sites in four areas including Bafang Port, Lvjiang Port, Moon Bay and Zhushan Bay, northwestern Lake Taihu. The results showed that the potential release rates of sediments can be efficiently prevented by dredging because of the internal loadings such as the loss on ignition, total nitrogen and ammonium nitrogen which were significantly lower after dredging. The potential release rates of ammonium in dredged sites of Bafang Port, Moon Bay and Zhushan Bay was 65. 3\% , $88.8 \%$ and $21.9 \%$, respectively. The potential release rates of phosphorus in dredged sites of Bafang Port even showed negative $\left(-0.35 \mathrm{mg} /\left(\mathrm{m}^{2} \cdot \mathrm{d}\right)\right)$ which means the diffusion direction of phosphorus was from overlying water toward sediments. The release rates of phosphorus in dredged sites of Moon Bay and Zhushan Bay was 11.3\% and 50.2\% of the corresponding un-dredged sites. We also found that the potential release rates of ammonium and phosphorus in dredged sites of Lvjiang Port was significantly higher than those in un-dredged sites, which may be accounted for the reducing environment of water body and the high content of organic matter in sediments.
\end{abstract}

* 国家水体污染控制与治理科技重大专项项目 (2012ZX07101-010,2013ZX07113-001)、国家自然科学基金项目 $(41171367,40901253)$ 、江苏省基础研究计划项目 (BK2011879) 和中国科学院南京地理与湖泊研究所科研启动项 目 (NIGLAS2011QD09) 联合资助. 2013-10-11 收稿;2014-03-03 收修改稿. 陈超 (1988 ), 男, 硕士研究生; E-mail:chaochenhc@163.com.

** 通信作者;E-mail:jczhong@ niglas. ac. cn. 
Keywords: Sediment dredging; potential release rates; effects evaluation; Lake Taihu

湖泊底泥是水生生态系统的重要组成部分, 是营养盐、重金属、持久性有机污染物的重要蓄积库, 同时 也是湖泊污染的潜在污染源. 而底泥影响湖泊水质的方式主要是通过内源释放, 已有研究表明内源释放对 太湖水体中氮、磷污染的贡献率为 $1 / 4^{[1]}$. 底泥疏浚因其能将湖泊表层污染严重的沉积物移出水体而常被用 于湖泊沉积物内源污染的治理, 目前我国已有多个湖泊实施和计划实施生态疏浚工程以期达到控制内源释 放和降低湖泊富营养化程度的目的. 其中太湖自 2007 年下半年以来分别于梅梁湾、竺山湾、贡湖、东太湖、 西部沿岸带和月亮湾等湖区进行了生态疏浚工程, 清淤面积达到 $36.80 \mathrm{~km}^{2}$, 疏浚量为 $1005.3 \times 10^{4} \mathrm{~m}^{3}$.

但疏浚工程对底泥污染的控制效果却因湖泊沉积物性质, 疏浚的深度、季节、方式 ${ }^{[2]}$ 的差异以及疏浚过 程中引起的二次释放与扩散 ${ }^{[3]}$ 而存在很大的争议. 研究表明, 疏浚能有效减少水体中总磷 ( TP) 以及叶绿素 $\mathrm{a}$ 的浓度 ${ }^{[4]}$, 同时降低沉积物营养盐的潜在释放速率 ${ }^{[5]}$. 钟继承等通过为期一年的模拟实验也发现, 疏浚对 沉积物营养盐潜在释放速率的控制效果在时间尺度上是逐渐增加的, 在外源输人得到控制的前提下, 疏浚 是沉积物污染修复的有效手段之一 ${ }^{[6]}$. 但也有研究认为疏浚促进了沉积物污染物的释放, 在短期内对湖泊 水生态环境造成一定的压力 ${ }^{[7-8]}$, 而富营养化本质上还是生态问题, 需要用生态的方法来解决 ${ }^{[9]}$. Ruley 等也 认为疏浚一段时间后, 底泥中的磷释放会恢复到以前的水平, 使水质重新恶化 ${ }^{[4]}$. 范成新等的研究也发现, 沉积物在一年的时间内同时扮演着污染物源和汇的角色 ${ }^{[1]}$. 由于疏浚工程投资相对较大, 疏浚后沉积物内 源释放等问题一直存在争议, 为了研究疏浚后水环境质量的变化以及评估疏浚对水环境质量的改善效应, 本文采集太湖问江口、八房港、月亮湾以及竺山湾疏浚区和未疏浚区沉积物柱状样, 于室内模拟静态释放实 验, 分析疏浚对上覆水体营养盐及沉积物性质的影响, 以期为疏浚方案的制定及工程的实施提供科学依据, 为疏浚后水环境质量的评估提供参考依据.

\section{1 材料与方法}

\section{1 样品采集}

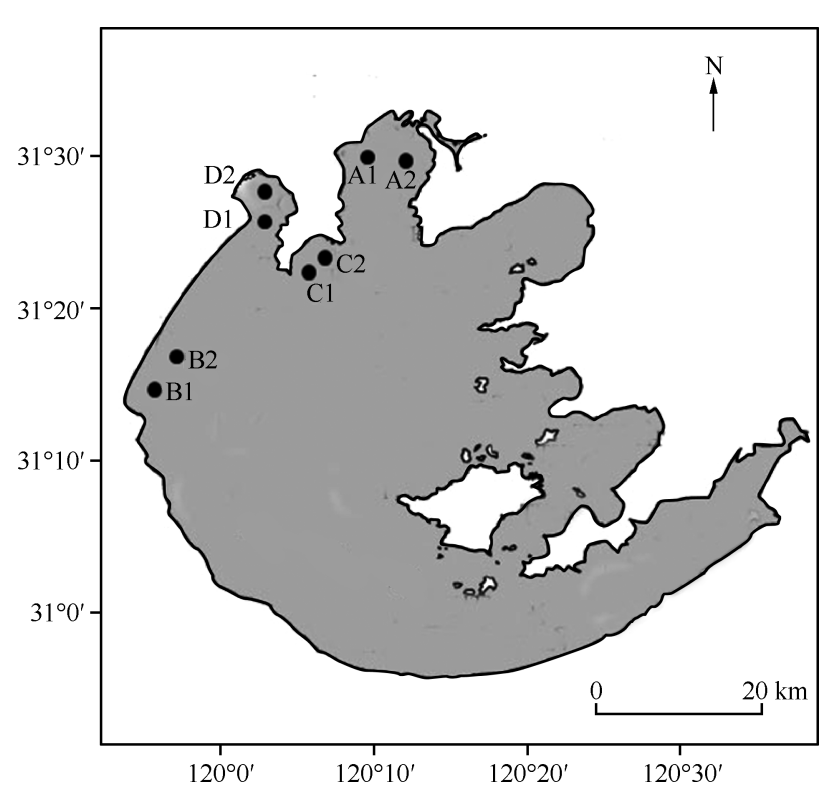

图 1 太湖采样点分布

Fig. 1 Distribution of sampling sites in Lake Taihu
用重力式柱状样采泥器于 2013 年 7 月初采集太湖问江口 (A)、八房港 (B)、月 亮湾 $(\mathrm{C})$ 以及竺山湾 $(\mathrm{D})$ 疏浚区和未疏浚 对照区 (分别用数字 1 和 2 代表) (图 1 ) 沉 积物柱状样品, 泥深控制在 $30 \mathrm{~cm}$ 左右并 带原位上覆水约 $20 \mathrm{~cm}$, 同时用 $25 \mathrm{~L}$ 聚乙烯 水桶采集原位水样并于 $5 \mathrm{~h}$ 内运回实验室 分析. 采样和运输过程中采取了相应的措 施以尽量避免沉积物界面发生扰动.

\section{2 沉积物一水界面微环境释放实验}

采用虹吸法将沉积物柱状样上层水抽 去后, 缓慢滴注过滤后的原采样点水样至 液面高度距沉积物表面 $20 \sim 30 \mathrm{~cm}$ 处停止 并标注刻度. 静置 $24 \mathrm{~h}$ 后于 $0 、 12 、 24 、 36$ 、 $48 、 72 \mathrm{~h}$ 时采集水样, 再以过滤后的原采样 点水样补充至水面刻度线. 采集的水样经 Whatman GF/F 滤膜过滤后储存于 $4^{\circ} \mathrm{C}$ 冰箱 待测. 实验结束后按 $2 \mathrm{~cm}$ 间隔将沉积物分 层, 测定沉积物基本理化性质及表层 $10 \mathrm{~cm}$ 可交换态氮和可交换态磷的含量. 


\section{3 分析方法}

采用纳氏试剂比色法测定上覆水体中

铵态氮 $\left(\mathrm{NH}_{4}^{+}-\mathrm{N}\right)$ 含量, 采用锄锑抗分光光度法 ( SHIMADZU, UV-2550) 测定正磷酸盐 $\left(\mathrm{PO}_{4}^{3-}-\mathrm{P}\right)$ 含量 ${ }^{[10]}$. 沉积 物含水率 (\%, 质量分数) 在 $105^{\circ} \mathrm{C}$ 条件下烘 $24 \mathrm{~h}$ 至恒重测定, 孔隙率和容重采用金属环刀法测定 ${ }^{[11]}$, 烧失量 采用烘干的沉积物放人马弗炉中在 $550^{\circ} \mathrm{C}$ 条件下灼烧 $6 \mathrm{~h}$ 的方法测定 ${ }^{[12]}$. 沉积物 TP 含量的测定方法参考文 献 [13], 以 $3.5 \mathrm{~mol} / \mathrm{L}$ 的盐酸提取 $550^{\circ} \mathrm{C}$ 灼烧后的沉积物 $16 \mathrm{~h}$, 离心后取上清液采用钿锑抗分光光度法测 定. 表层可交换态磷含量利用 $\mathrm{NH}_{4} \mathrm{Cl}$ 溶液提取后比色测定 ${ }^{[14]}$. 采用过硫酸钾消解紫外分光光度法测定沉积 物总氮 $(\mathrm{TN})$ 含量 ${ }^{[10]}$, 沉积物可交换态氮的含量利用 $\mathrm{KCl}$ 溶液提取后比色测定 ${ }^{[15]}$.

\section{4 数据分析与统计检验}

数据分析与绘图分别使用 Excel 2007 和 Origin 8.5 软件;沉积物一水界面营养盐潜在释放速率计算方法 参照文献 [15],各研究湖区疏浚区与对照区沉积物一水界面营养盐通量的统计检验使用软件 SPSS 20.

\section{2 结果与分析}

\section{1 沉积物基本理化性质}

各湖区沉积物中含水率、孔隙度和烧失量均表现出疏浚区低于未疏浚对照区的特征,容重则表现出相 反的特征(表 1).八房港、问江口、月亮湾和笈山湾疏浚区沉积物含水率分别是相应未疏浚区沉积物的 $74.4 \% 、 65.8 \% 、 93.4 \%$ 和 $93.1 \%$, 其中问江口表层的含水率较低, 且疏浚区和未疏浚区含水率差异最大. 竺 山湾未疏浚区沉积物烧失量最高, 平均达到了 $7.5 \%$,为疏浚区沉积物的 1.08 倍. 问江口疏浚区和未疏浚区 沉积物烧失量随深度增加逐渐减少,其余湖区垂向分布不明显.

问江口疏浚区沉积物 TP 含量要大于未疏浚区, 为未疏浚区的 1.4 倍, 其余采样点疏浚区沉积物 TN、TP 含量大都低于未疏浚区. 竺山湾沉积物 TN 和 TP 含量要明显高于其余采样点, 最高值分别达到了 2914.4 和 $1635.7 \mathrm{mg} / \mathrm{kg}$, 表明竺山湾一带受人湖污染源影响较大, 人湖 TN 、 TP 分别占全太湖人湖总量的 $43.1 \%$ 和 $31.3 \%$, 是太湖沿岸污染源最集中的区域 ${ }^{[16]}$.

\section{表 1 太湖各采样点沉积物基本理化性质*}

Tab. 1 Physicochemical characteristic of each sediment sampling site in Lake Taihu

\begin{tabular}{cccccccc}
\hline 样点 & 深度/cm & 含水率/\% & 容重/\% & 孔隙度/\% & 烧失量 $/ \%$ & $\mathrm{TP} /(\mathrm{mg} / \mathrm{kg})$ & $\mathrm{TN} /(\mathrm{mg} / \mathrm{kg})$ \\
\hline 八房港 & $0 \sim 2$ & $59.0(46.3)$ & $1.4(1.6)$ & $78.3(68.3)$ & $3.4(3.2)$ & $422.1(306.1)$ & $1963.3(1215.6)$ \\
& $2 \sim 4$ & $56.9(43.4)$ & $1.5(1.7)$ & $74.7(60.2)$ & $2.8(2.5)$ & $407.2(276.9)$ & $2057.9(1173.9)$ \\
& $4 \sim 6$ & $55.6(39.7)$ & $1.4(1.6)$ & $72.6(61.6)$ & $4.5(3.5)$ & $348.2(273.9)$ & $1974.1(1340.5)$ \\
& $6 \sim 8$ & $54.2(37.7)$ & $1.3(1.6)$ & $75.8(62.2)$ & $5.5(3.5)$ & $360.9(324.8)$ & $2169.3(1442.0)$ \\
问江口 & $8 \sim 10$ & $51.4(39.1)$ & $1.4(1.5)$ & $76.8(65.7)$ & $5.6(4.0)$ & $400.4(346.8)$ & $2280.7(1772.9)$ \\
& $0 \sim 2$ & $55.3(37.7)$ & $1.6(1.9)$ & $75.5(60.2)$ & $5.3(4.5)$ & $411.3(639.7)$ & $1201.2(1046.8)$ \\
& $2 \sim 4$ & $48.3(31.7)$ & $1.5(1.8)$ & $70.0(53.7)$ & $5.2(3.8)$ & $446.4(625.3)$ & $1705.2(1056.5)$ \\
& $4 \sim 6$ & $46.6(29.4)$ & $1.5(1.7)$ & $68.6(50.9)$ & $5.2(3.6)$ & $438.7(623.4)$ & $1798.7(1012.9)$ \\
& $6 \sim 8$ & $45.7(29.8)$ & $1.6(1.9)$ & $67.8(51.4)$ & $5.2(3.4)$ & $431.3(629.5)$ & $1646.5(1100.9)$ \\
月亮湾 & $8 \sim 10$ & $42.7(28.5)$ & $1.5(2.0)$ & $65.1(49.9)$ & $5.0(3.0)$ & $433.8(603.9)$ & $1831.5(1042.4)$ \\
& $0 \sim 2$ & $54.9(54.7)$ & $1.4(1.4)$ & $75.3(75.1)$ & $3.9(3.6)$ & $337.8(406.5)$ & $1804.7(1719.1)$ \\
& $2 \sim 4$ & $51.4(47.4)$ & $1.5(1.4)$ & $72.6(69.3)$ & $3.7(3.8)$ & $382.6(359.5)$ & $1597.4(1859.1)$ \\
& $4 \sim 6$ & $47.3(46.2)$ & $1.6(1.6)$ & $69.2(68.2)$ & $3.9(3.4)$ & $302.5(329.2)$ & $1805.7(1630.6)$ \\
& $6 \sim 8$ & $52.9(43.9)$ & $1.5(1.4)$ & $73.8(66.2)$ & $3.8(4.5)$ & $571.2(332.7)$ & $1628.6(1607.3)$ \\
& $8 \sim 10$ & $47.5(45.1)$ & $1.5(1.4)$ & $69.3(67.3)$ & $4.2(4.2)$ & $406.9(378.1)$ & $1769.5(2005.4)$ \\
䇥山湾 & $0 \sim 2$ & $67.8(62.8)$ & $1.3(1.4)$ & $84.1(80.8)$ & $7.4(6.3)$ & $1458.9(1462.9)$ & $2914.4(2797.7)$ \\
& $2 \sim 4$ & $59.9(53.9)$ & $1.4(1.4)$ & $78.9(74.5)$ & $7.3(6.7)$ & $1635.7(1276.5)$ & $2793.2(2652.7)$ \\
& $4 \sim 6$ & $57.9(55.6)$ & $1.5(1.4)$ & $77.5(75.8)$ & $7.8(7.4)$ & $1627.5(1203.2)$ & $2609.2(2181.6)$ \\
& $6 \sim 8$ & $57.0(51.9)$ & $1.3(1.5)$ & $76.8(72.9)$ & $7.6(7.5)$ & $1565.7(994.6)$ & $2714.0(2972.7)$ \\
& $8 \sim 10$ & $55.0(47.8)$ & $1.5(1.5)$ & $75.3(69.6)$ & $7.7(6.9)$ & $1385.2(1286.6)$ & $2864.6(2723.5)$ \\
& $10 \sim 12$ & $55.8(46.1)$ & $1.4(1.6)$ & $75.9(68.1)$ & $7.3(6.3)$ & $1431.4(1065.4)$ & $2673.9(2465.7)$ \\
\hline
\end{tabular}

* 括号外为未疏浚区沉积物的数据, 括号内为对应疏浚区沉积物的数据. 


\section{2 表层沉积物 $\mathrm{NH}_{4}^{+}-\mathrm{N}$ 含量}

沉积物中的氮可以分为有机态和无机态, 其中有机态是沉积物中氮的主要组成部分, 而 $\mathrm{NH}_{4}^{+}-\mathrm{N}$ 是无机 态氮的主要组成部分, 并且 $\mathrm{NH}_{4}^{+}-\mathrm{N}$ 属于生物有效性氮, 是沉积物中氮的最活跃形态, 可以直接被生物利用, 在氮的生物地球化学循环中起着重要作用 ${ }^{[17]}$. 本次实验样品均采集于太湖西北沿岸污染较重的区域, 沉积 物中 $\mathrm{NH}_{4}^{+}-\mathrm{N}$ 含量较高. 但不同区域表层沉积物中 $\mathrm{NH}_{4}^{+}-\mathrm{N}$ 含量存在一定的差异, 竺山湾沉积物样品中 $\mathrm{NH}_{4}^{+}-\mathrm{N}$ 含量要高于月亮湾、八房港和问江口 (图 2), 这可能与竺山湾历史上的水产养殖 ${ }^{[18]}$ 、河流输人以及藻类碎屑 物等积累有很大关系.

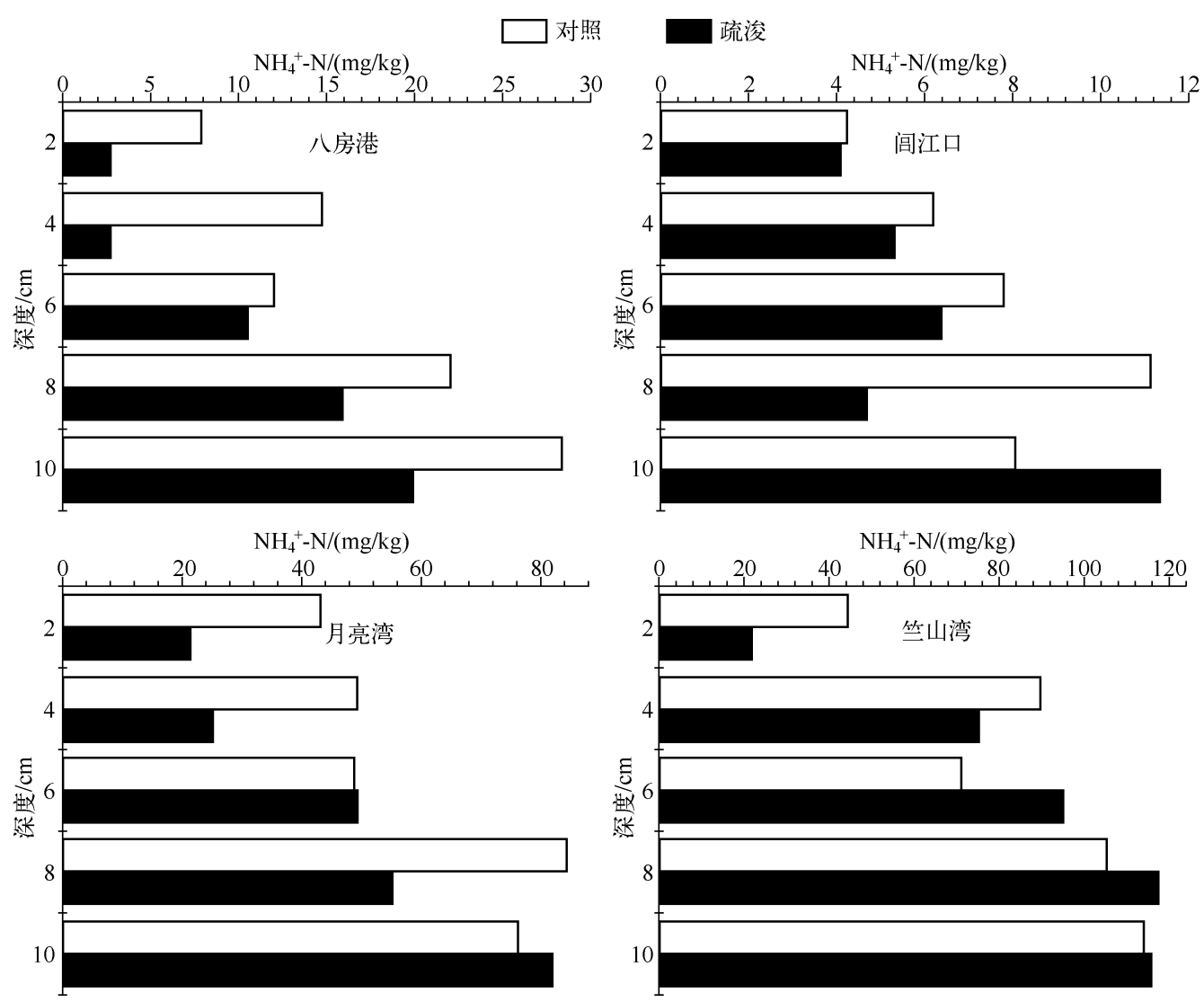

图 2 太湖各采样点沉积物 $\mathrm{NH}_{4}^{+}-\mathrm{N}$ 含量

Fig. 2 Ammonium content of each sediment sampling site in Lake Taihu

不同采样点位沉积物样品中 $\mathrm{NH}_{4}^{+}-\mathrm{N}$ 含量的垂向分布均表现为随着沉积物深度的增加而增加, 疏浚后 沉积物样品中 $\mathrm{NH}_{4}^{+}-\mathrm{N}$ 含量低于相应点位的未疏浚对照区 (图 2). 八房港、问江口、月亮湾和竺山湾疏浚区沉 积物 $\mathrm{NH}_{4}^{+}-\mathrm{N}$ 含量分别是对照区的 $61.1 \% 、 85.1 \% 、 91.9 \%$ 和 $98.9 \%$. 沉积物中氮的溶出与生物作用大小、氧 化还原状况及含氮化合物氧化分解程度有关 ${ }^{[19]}$, 未疏浚沉积物表层底泥有机质含量丰富, 在微生物的分解 作用下易使表层形成还原环境, 促进沉积物中的 $\mathrm{NH}_{4}^{+}-\mathrm{N}$ 向水体释放, 而水体中植物、微生物和鱼类对 $\mathrm{NH}_{4}^{+}-\mathrm{N}$ 的吸收也加速了这一过程的进行, 同时表层微生物的反硝化作用使水体中的氮元素以 $\mathrm{N}_{2} 、 \mathrm{NO}_{2}$ 和 $\mathrm{NO}_{3}$ 等气态形式逸出水面 ${ }^{[20]}$. 疏浚使曾埋藏于水底的深层沉积物直接与上覆水体接触, 在风浪扰动作用下 使新生界面频繁与含氧高的介质接触 ${ }^{[21]}$, 致使表层沉积物氧化还原电位升高, 抑制了营养盐的释放. 但是由 于疏浚过程中的残留淤泥及悬浮于上覆水体的富含有机质的颗粒物的沉降, 新生表层微生物活动加强, 氨 化和反硝化作用加强, 从而使沉积物表层的 $\mathrm{NH}_{4}^{+}-\mathrm{N}$ 以气态形式逸出水面, 降低了表层 $\mathrm{NH}_{4}^{+}-\mathrm{N}$ 含量 ${ }^{[22-23]}$. 下 
层沉积物由于缺氧程度较高, 高价态的氮 (如 $\mathrm{NO}_{3}^{-}-\mathrm{N}$ ) 易于向低价态转化, 并且下层受水动力扰动较小, 比 上层沉积物更有利于 $\mathrm{NH}_{4}^{+}-\mathrm{N}$ 在沉积层中的保存 ${ }^{[24]}$. 成刚通过对太湖柱状沉积物垂向分析也发现, 间隙水中 $\mathrm{NH}_{4}^{+}-\mathrm{N}$ 含量也呈现出随深度的增加逐渐增大的现象 ${ }^{[25]}$.

\section{3 表层沉积物可交换态磷含量}

可交换态磷主要指与沉积物中的氧化物、氢氧化物以及黏土矿物等物质通过吸附或共沉淀作用相互结 合的磷 ${ }^{[26]}$, 这部分形态磷可通过释放作用直接与沉积物一水界面进行物质交换,或通过再悬浮作用被带到上 覆水体中,被水生生物吸收利用, 直接参与生态系统循环, 是底泥中最具活性的一类磷形态 ${ }^{[27]}$.

沉积物中可交换态磷含量 (本文以 $\mathrm{PO}_{4}^{3-}-\mathrm{P}$ 形态表示) 均较低 (图 3), 问江口未疏浚沉积物表层 $10 \mathrm{~cm}$ 平 均含量最低, 仅为 $3.6 \mathrm{mg} / \mathrm{kg}$, 而其相应的疏浚区沉积物表层 $10 \mathrm{~cm}$ 可交换态磷的含量却远高于未疏浚区, 达 到了 $10.2 \mathrm{mg} / \mathrm{kg}$. 这可能是问江口疏浚区沉积物 $\mathrm{PO}_{4}^{3-}-\mathrm{P}$ 潜在释放速率高于未疏浚区沉积物的主要原因 (图 4).八房港疏浚区与未疏浚区沉积物表层 $10 \mathrm{~cm}$ 可交换态磷含量相近, 平均值分别为 4.0 和 $3.9 \mathrm{mg} / \mathrm{kg}$, 竺山 湾疏浚区与未疏浚区分别为 15.2 和 $16.4 \mathrm{mg} / \mathrm{kg}$. 而月亮湾样点沉积物则表现出疏浚区可交换态磷的含量 低于未疏浚区的特征,平均值分别为 5.1 和 $8.2 \mathrm{mg} / \mathrm{kg}$.

从可交换态磷含量的垂向分布来看, 8 个采样点沉积物柱状样的变化曲线大致可以分为两类:八房港和 月亮湾疏浚区与未疏浚区沉积物中可交换态磷含量表现为从深部到表层呈 $\mathrm{S}$ 型变化,竺山湾处沉积物中 $\mathrm{PO}_{4}^{3-}$ - $\mathrm{P}$ 含量则表现为自 $10 \mathrm{~cm}$ 处向表层逐渐增加. 本实验样品采集于蓝藻暴发时节, 蓝藻的死亡分解以及 因此造成的表层沉积物氧化还原点位的降低都会促使沉积物表层可交换态磷含量的增加. 太湖人湖生物体 残留率达到了 6.80 (净人湖量: 湖体原有量) ${ }^{[28]}$, 使得一些溶解或颗粒态的含磷物质通过絮凝、吸附以及沉 降等作用蓄积于沉积物, 从而逐渐增加沉积物表层磷的含量. 太湖北部地区历史上曾有大量水生植物生 长 ${ }^{[29]}$, 死亡生物体中有机磷 ( Org-P) 的降解以及其他形态磷的转化会增加沉积物中可交换态磷的含量. 而疏 浚使埋藏于深部的含磷量较高的沉积物暴露于水界面. 这可能是问江口疏浚区沉积物样品可交换态磷远高 于未疏浚区的主要原因之一.

\section{4 沉积物 - 水界面 $\mathrm{NH}_{4}^{+}-\mathrm{N} 、 \mathrm{PO}_{4}^{3-}-\mathrm{P}$ 的潜在释放速率}

不同湖区各点位沉积物 $\mathrm{NH}_{4}^{+}-\mathrm{N}$ 的潜在释放速率均为正值 (图 4), 即沉积物是上覆水体 $\mathrm{NH}_{4}^{+}-\mathrm{N}$ 的来源 之一, 这可能也是表层沉积物 $\mathrm{NH}_{4}^{+}-\mathrm{N}$ 含量低于深层沉积物的原因之一 (图 2). 对比疏浚区与相应未疏浚区 沉积物 $\mathrm{NH}_{4}^{+}-\mathrm{N}$ 的潜在释放速率发现,八房港、月亮湾和竺山湾疏浚区沉积物 $\mathrm{NH}_{4}^{+}-\mathrm{N}$ 的潜在释放速率均低 于相应未疏浚区的沉积物柱样, 平均值分别是 9.3 .35 .3 和 $3.6 \mathrm{mg} /\left(\mathrm{m}^{2} \cdot \mathrm{d}\right)$, 分别为相应未疏浚区沉积物的 $65.3 \% 、 88.8 \%$ 和 $21.9 \%$, 而问江口疏浚区沉积物 $\mathrm{NH}_{4}^{+}-\mathrm{N}$ 的潜在释放速率却远高于未疏浚区 ( 分别为 34.3 和 $\left.13.2 \mathrm{mg} /\left(\mathrm{m}^{2} \cdot \mathrm{d}\right)\right)$. 问江口沉积物表层有机质含量 (烧失量) 要高于深层沉积物 (表 1), 而含氮化合物由 于微生物的分解作用会导致沉积物需氧量增加, 从而形成缺氧和厌氧环境, 促进 $\mathrm{NH}_{4}^{+}-\mathrm{N}$ 的释放.

不同湖区沉积物 $\mathrm{PO}_{4}^{3-}-\mathrm{P}$ 的潜在释放速率与 $\mathrm{NH}_{4}^{+}-\mathrm{N}$ 潜在释放速率相似 (图 4). 八房港、月亮湾和竺山湾 沉积物样品 $\mathrm{PO}_{4}^{3-}-\mathrm{P}$ 的潜在释放速率均表现为疏浚区低于未疏浚区的特征, 疏浚区分别为未疏浚区的 $-26.6 \% 、 11.3 \%$ 和 $50.2 \%$, 在八房港疏浚区甚至出现了负值 $\left(-0.35 \mathrm{mg} /\left(\mathrm{m}^{2} \cdot \mathrm{d}\right)\right)$, 说明 $\mathrm{PO}_{4}^{3-}-\mathrm{P}$ 的扩散 方向是由水体到沉积物, 此时沉积物是水体 $\mathrm{PO}_{4}^{3-}-\mathrm{P}$ 的汇而不是源. 月亮湾未疏浚区沉积物 $\mathrm{PO}_{4}^{3-}-\mathrm{P}$ 的潜在 释放速率要远高于其余沉积物样品, 达到了 $17.1 \mathrm{mg} /\left(\mathrm{m}^{2} \cdot \mathrm{d}\right)$. 研究表明, 月亮湾北部呈还原状态 ${ }^{\left[{ }^{30]}\right.}$, 而沉 积物磷的迁移转化与沉积物中铁、铝氧化矿物的吸附解吸有直接的关系, 当氧化还原电位降低时, 沉积物中 与 $\mathrm{Fe}^{3+}$ 相结合的形态磷会转化为 $\mathrm{PO}_{4}^{3-}-\mathrm{P}$, 增加间隙水与上覆水体中 $\mathrm{PO}_{4}^{3-}-\mathrm{P}$ 的浓度梯度, 促进沉积物中 $\mathrm{PO}_{4}^{3-}-\mathrm{P}$ 的释放, 这也可能是月亮湾表层沉积物 $\mathrm{PO}_{4}^{3-}-\mathrm{P}$ 含量较低的原因之一(图 3). 而问江口疏浚区沉积物 $\mathrm{PO}_{4}^{3-}-\mathrm{P}$ 的潜在释放速率却远高于未疏浚区 (疏浚区潜在释放速率为未疏浚区的 6.4 倍), 这可能与问江口 疏浚区沉积物 TP ( 表 1 ) 和可交换态磷含量高于未疏浚区沉积物(图 3) 有直接关系.

八房港以及月亮湾疏浚工程实施的时间分别为 2012 年 8-10 月和 2010 年 11 月,对于太湖这样的大型 浅水湖泊来说, 风浪扰动作用使疏浚后的新生表层界面与含氧量高的介质充分接触,随着时间的推移表层 逐渐形成较致密的氧化层 ${ }^{[21]}$, 并且由于疏浚后沉积物一水界面溶解氧的穿透深度增加 ${ }^{[31]}$, 使疏浚后下层沉 


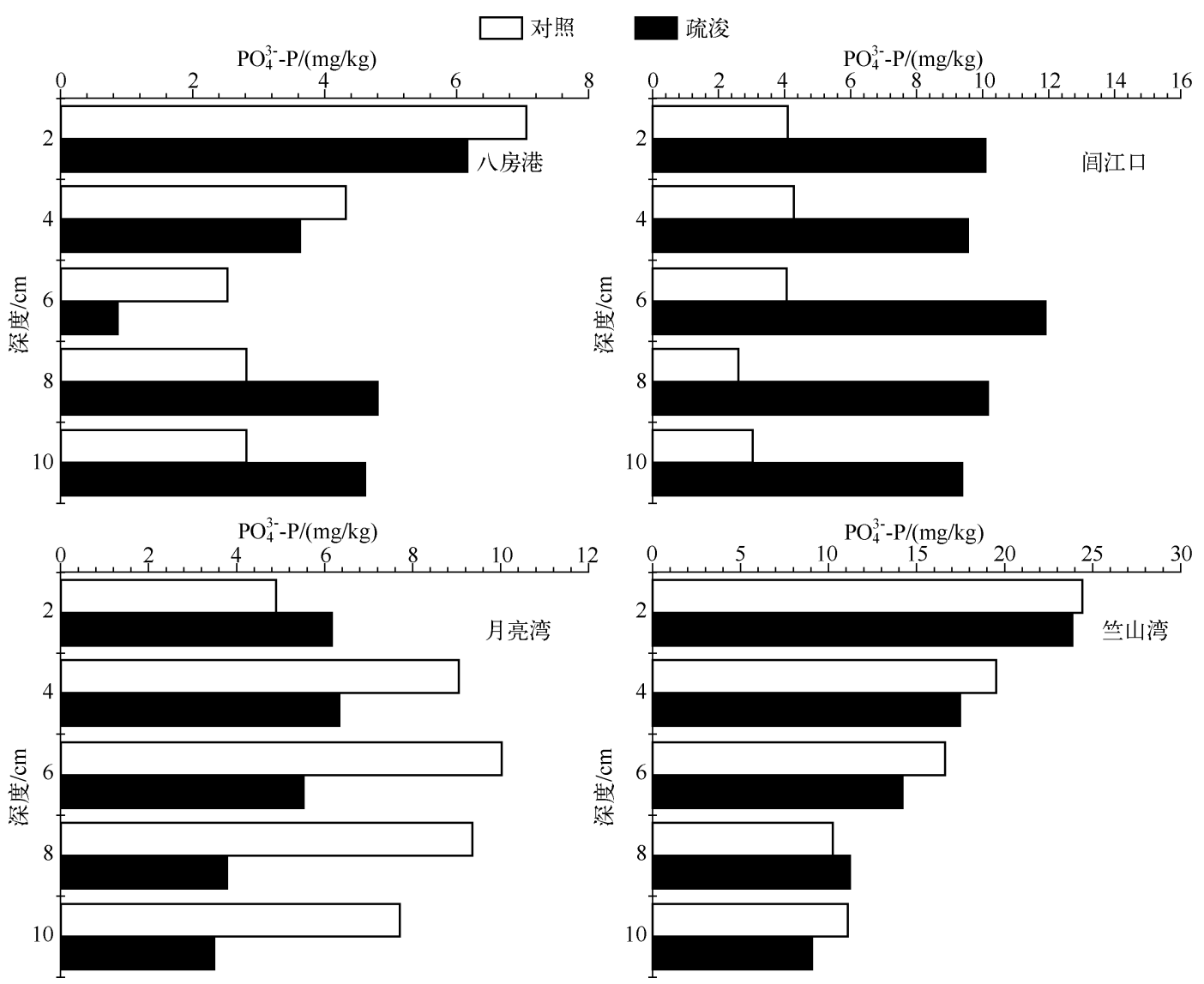

图 3 太湖各采样点沉积物可交换态磷含量

Fig. 3 Phosphate content of each sediment sampling site in Lake Taihu

积物溶解氧含量较高, 抑制氮、磷的潜在释放速率. 而问江口疏浚的时间为 2013 年 3-5 月, 疏浚时间较短, 疏浚初期深层沉积物和间隙水中氮、磷营养盐的含量均远高于上覆水体 ${ }^{[32-33]}$, 利于沉积物氮、磷等营养盐潜

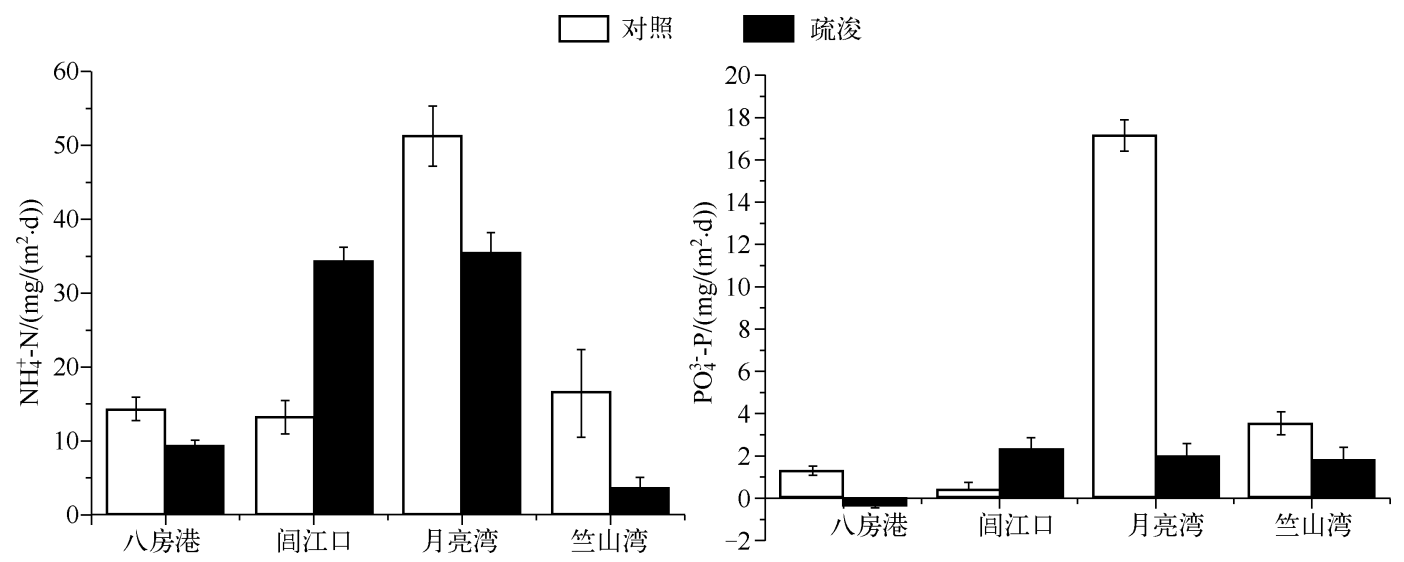

图 4 太湖各采样点沉积物一水界面 $\mathrm{NH}_{4}^{+}-\mathrm{N} 、 \mathrm{PO}_{4}^{3-}-\mathrm{P}$ 的潜在释放速率

Fig. $4 \mathrm{NH}_{4}^{+}-\mathrm{N}$ and $\mathrm{PO}_{4}^{3-}-\mathrm{P}$ release rates of the sediment-water interface of each sampling site in Lake Taihu 
在释放速率的增加 ${ }^{[24]}$, 所以在疏浚初期问江口沉积物 $\mathrm{NH}_{4}^{+}-\mathrm{N} 、 \mathrm{PO}_{4}^{3-}-\mathrm{P}$ 的潜在释放速率要略高于未疏浚对照 区, 这与钟继承等为期一年的模拟实验结果相类似 ${ }^{[6,32]}$. 另外北部湖区沉积物营养盐含量空间差异较大,一 般靠近人湖河口附近的沉积物营养盐含量相对较高, 如果疏浚深度不够, 可能就没有把表层污染较为严重 的沉积物清除出水体, 反而促进了沉积物氮、磷的潜在释放速率. 申霞等研究发现, 风浪扰动过程中底泥再 悬浮量与沉积物容重表现出明显的负相关关系 ${ }^{[34]}$, 而疏浚后的沉积物容重均大于未疏浚沉积物 (表 1 ), 有 利于抑制风浪作用下颗粒物的再悬浮以及因此而引发的氮、磷等营养物质的二次释放. 通过单因素方差分 析发现, 疏浚区与相应未疏浚区沉积物 $\mathrm{NH}_{4}^{+}-\mathrm{N} 、 \mathrm{PO}_{4}^{3-}-\mathrm{P}$ 的潜在释放速率差异显著 $(P<0.05)$, 说明疏浚能有 效地控制沉积物一水界面营养盐的潜在释放速率, 对水体营养盐浓度的减少具有一定的积极作用.

\section{3 结论}

疏浚可有效减少沉积物中有机质和营养盐的含量,降低沉积物营养盐的释放潜力,不同区域疏浚后沉 积物营养盐的潜在释放速率有所差异. 疏浚工程对八房港、月亮湾以及竺山湾沉积物 $\mathrm{NH}_{4}^{+}-\mathrm{N} \mathrm{PO}_{4}^{3-}-\mathrm{P}$ 的潜 在释放速率具有较好的控制效果,其疏浚区沉积物氮、磷的潜在释放速率均明显低于对照区,而问江口则呈 现相反的特征,这可能与该湖区沉积物污染物的赋存特征、疏浚时间和水环境的差异有一定的关系,疏浚方 法和疏浚质量以及疏浚过程中淤泥的回流也与疏浚后沉积物内源释放有直接的关系. 总的来说, 在外源污 染物的输人得到有效控制的前提下, 在重污染湖区开展生态疏浚对沉积物内源负荷控制具有积极的作用.

\section{4 参考文献}

[ 1 ] 范成新, 张 路,包先明等. 太湖沉积物一水界面生源要素迁移机制及定量化-2. 磷释放的热力学机制及源一汇 转换. 湖泊科学, 2006,18 (1):207-217.

[2] 颜昌宙,范成新,杨建华等. 湖泊底泥环保疏浚技术研究展望. 环境污染与防治,2007,26(3):189-192.

[ 3 ] Lohrer AM, Wetz JJ. Dredging-induced nutrient release from sediments to the water column in a southeastern saltmarsh tidal creek. Marine Pollution Bulletin, 2003 ,46(9):1156-1163.

[ 4 ] Ruley JE, Rusch KA. An assessment of long-term post-restoration water quality trends in a shallow, subtropical, urban hypereutrophic lake. Ecological Engineering, 2002 ,19(4):265-280.

[ 5 ] Desprez M. Physical and biological impact of marine aggregate extraction along the French coast of the Eastern English Channel: shortand long-term post-dredging restoration. ICES Journal of Marine Science, 2000 ,57 (5) : 1428-1438.

[ 6 ] 钟继承,刘国锋,范成新等. 湖泊底泥疏浚环境效应: I. 内源磷释放控制作用. 湖泊科学, 2009,21(1):84-93.

[ 7 ] 刘爱菊,孔繁翔,王 栋等. 太湖底泥疏浚的水环境质量风险性分析. 环境科学,2006,27(10):1947-1952.

[ 8 ] Nayar S, Miller DJ, Hunt A et al. Environmental effects dredging on sediment nutrients, carbon and granulometry in a tropical estuary. Environmental Monitor Assessment,2007,127:1-13.

[ 9 ] 陆 子. 湖泊底泥挖掘可能导致氮磷平衡破坏的研究. 中国环境监测, 2001,17(2):40-42.

[10］金相灿,屠清瑛. 湖泊富营养化调查规范:第 2 版. 北京:中国环境科学出版社, 1990 .

[11] Graca B, Burska D, Matuszewska K. The impact of dredging deep pits on organic matter decomposition in sediments. Water, Air, and Soil Pollution, 2004 ,158(1):237-259.

[12］张文河,穆桂金. 烧失法测定有机质和碳酸盐的精度控制. 干旱区地理,2007,30(3):454-458.

[13 ] Ruban V, Lopez-Sanchez JF, Pardo P et al. Selection and evaluation of sequential extraction procedures for the determination of phosphorus forms in lake sediment. Journal of Environment Monitoring, 1998,1:51-56.

[14] Rydin E. Potentially mobile phosphorus in lake Erken sediment. Water Research, 2000,34(7) :2037-2042.

[15] Lu X, Song J, Li X et al. Geochemical characteristics of nitrogen in the southern Yellow Sea surface sediments. Journal of Marine Systems, 2005,56(1/2):17-27.

[16] 范成新. 太湖水体生态环境历史演变. 湖泊科学, 1996,8(4):297-304.

[17] Wang PF,Zhao L, Wang C et al. Nitogen distribution and potential mobility in sediments of three typical shallow urban lakes in China. Environmental Engineering Science, 2009,26(10) : 1511-1521.

[18］袁旭音,陈 骏,陶于祥等. 太湖北部底泥中氮、磷的空间变化和环境意义. 地球化学,2002,31(4):321-328.

[19] 欧阳媛,王圣瑞,金相灿等. 外加氮源对滇池沉积物氮矿化影响的研究. 中国环境科学, 2009,29(28):879-884. 
[20] Mayer LM, Macko SA, Cammen L. Provenance, concentrations and nature of sedimentary organic nitrogen in the Gulf of Maine. Marine Chemistry, 1988,25 ( 5 ) :291-304.

[21] 李文红, 陈英旭, 孙建平等. 疏浚对影响底泥向上覆水体释放污染物的研究. 农业环境科学学报, 2003,22(4): 446-448.

[22] Lourey MJ, Alongi DM, Ryan DAJ. Variability of nutrient regeneration rates and nutrient concentrations in surface sediments of the northern Great Barrier Reef shelf. Continental Shelf Research, 2001,21 (4) : 145-155.

[23 ] Michel D. Physical and biological impact of marine aggregate extraction along the French coast of Eastern English Channel: short and long-term post-dredging restoration. Journal of Marine Science, 2000,57 ( 5 ) :1428-1438.

[24] 俞海桥,方 涛, 夏世斌等. 不同生态修复措施下太湖西五里湖沉积物氮磷形态的时空分布. 湖泊科学, 2007, 19 (6) :683-689.

[25] 成 刚. 太湖氮营养盐的分布特征及区域差异性研究 [学位论文]. 兰州: 兰州大学,2010.

[26] Lai DY, Lam KC. Phosphorus retention and release by sediments in the eutrophic Mai Po Marshes, Hong Kong. Marine Pollution Bulletin, 2008, 57(6-12):349-356.

[27] Kaiserli A, Voutsa D, Samara C. Phosphorus fractionation in lake sediments-lakes Volvi and Koronia, N. Greece. Chemosphere, $2002, \mathbf{4 6}(8): 1147-1155$.

[28] 金相灿. 中国湖泊环境:第二册. 北京:海洋出版社,1995:112.

[29］伍献文. 五里湖 1951 年湖泊学调查. 水生生物学集刊,1962,1(1):63-113.

[30］孙顺才, 黄渏平. 太湖. 北京: 海洋出版社, 1993 .

[31] He W, Shang JG, Lu X et al. Effects of sludge dredging on the prevention and control of algae-caused black bloom in Taihu Lake,China. Journal of Environment Sciences, 2013,25 (3):430-440.

[32] 钟继承, 刘国锋, 范成新等. 湖泊底泥疏浚环境效应: II. 内源氮释放控制作用. 湖泊科学, 2009,21(3):335-344.

[33] 何 伟,商景阁, 周鹿麟等. 淀山湖底泥生态疏浚适宜深度判定分析. 湖泊科学, 2013,25(4):471-477.

[34] 申 霞,洪大林, 丁艳青等. 太湖疏浚前后波浪扰动下的底泥再悬浮特征. 水科学进展,2011,22(4) :580-585. 